Volume: 14 Issue: 2 Year: 2017

\section{Investigating the heart rate and oxygen saturation values of u13 category footballers at competition occasion who stand in different Uphill cities $^{1}$}

Farklı yükseltideki illerde bulunan u13 kategorisi futbolcuların müsabaka ortamında nabız ve oksijen saturasyon değerlerinin incelenmesi

\section{Yunus Emre Bağış ${ }^{2}$ \\ Mehmet Kumartaşli ${ }^{3}$}

\section{Özet}

Bu araştırmanın amacı, farklı yükseltideki illerde bulunan U13 kategorisi futbolcuların müsabaka şartlarında nabız ve oksijen saturasyon değerlerinin incelenmesidir.

Araştırmaya Ankara Keçiören Bağlum Spor (n 17) ve Isparta Iyaş Gençlik Sporun (n:17) U13 futbol takıminda oynayan toplam 34 futbolcu gönüllü (izinli) olarak katıldı. Araştırma grubundan boy, vücut ağırlığı, kalp atım sayısı ve $\mathrm{O}_{2}$ saturasyonu ölçümleri alındı. Elde edilen verilerin tanımlayıc1 istatistikleri ile gruplar arasında farkları belirlemek için Independent $t$ testi kullanıldı. Araştırmaya katılan sporcuların boy ortalaması Isparta Iyaş Gençlik ve Spor Kulübünde 156,1 $\pm 6,1 \mathrm{~cm}$, Ankara Bağlum Spor

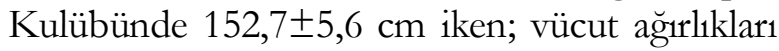
ortalamas1 Isparta Iyaş Gençlik ve Spor

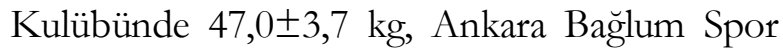
Kulübünde $48,4 \pm 4,0 \mathrm{~kg}$ olarak tespit edildi. Sporcuların müsabaka başlangicinda ve esnasinda kalp atım sayılarinin karşılaştırılmasında da fark anlamsız bulunmuştur $(\mathrm{p}>0.05)$. Sporcuların müsabaka öncesi ve müsabakanın 30. dakikasında oksijen saturasyonu ölçümlerinin karşılaştırılması sonucunda istatistiksel açıdan anlamlı fark

\footnotetext{
1 This paper is presented at III. International Sport Science, Tourism and Recreation Student Congress at Gaziantep University, May 27-29, 2016, Gaziantep.

2 Ph.D. Student, Sakarya University, Institute of Educational Sciences, Department of Physical Education and Sports, yunusemrebagis@hotmail.com

3 Assist. Prof. Dr, Suleyman Demirel University, Faculty of Sport Science, mehmetkmrtsl@hotmail.com
} 
Bağıș, Y. E., \& Kumartaşlı, M. (2017). Farklı yükseltideki illerde bulunan u13 kategorisi futbolcuların müsabaka ortamında nabız ve oksijen saturasyon değerlerinin incelenmesi. Journal of Human Sciences, 14(2), 1975-1982. doi:10.14687/jhs.v14i2.4133

we think that studying with more higher areas and groups will be useful for sharpening some differences and similarities.

Keywords: Football; Heart Rate; Oxygen Saturation.

(Extended English abstract is at the end of this document) bulunurken $(p<0.05)$, müsabakının öncesi ve 10., 20., 40. dakiklardaki oksijen saturasyonu ölçümlerinin karşılaştırılması sonucunda ise fark istatistiksel açıdan anlamlı fark bulunamamıştır $(\mathrm{p}>0.05)$. Elde edilen verilere dayanarak baz1 farkliliklarin veya benzerliklerin daha da netleşebilmesi için daha fazla yükseltiye sahip olan bölgeler ve gruplar üzerinde çalısılmasının yararlı olacağı düşünmekteyiz.

Anahtar Kelimeler: Futbol; Nabız; Oksijen Saturasyonu.

\section{Giriş}

Uzun süreli ve yüksek tempolu fiziksel aktiviteler sırasında sportif başarıyı yukarı taşıan belirleyici etkenler arasında maksimal oksijen (MaxVO2) alımının sayılması mümkündür. Özellikle aerobik metabolizmanın üst düzeyde zorlandığı fiziksel aktiviteler sırasında başarıyı belirleyen en önemli ölçütlerden birisi olan oksijen kullanabilme kapasitesi, esasta iskelet kas hücrelerinde mitokondrilerin çalışabilme yeteneğini ifade etmektedir.

Fiziksel yapının branşa özgün uyumluluğu ile fizyolojik kapasitenin yüksek olması performans açısından önemli kriterler içerisinde yer almaktadır. Futbol aerobik ve anaerobik sistemlerin yüksek düzeyde devreye girdiği bir spor branşıdır. Aerobik ve anaerobik dayanıklıllk düzeylerinin yüksek olması başarı için önemli olarak görülmektedir. Aerobik ve anaerobik dayanıklılık da maksimal oksijen tüketimi (Max.V02) ile sınırlıdır. Sporcuların solunum fonksiyonları özellikle vital kapasite (VC) aerobik ve anaerobik dayanıklıllk hakkında bilgi vermektedir. Fiziksel egzersizde kasların oksijen ihtiyacı artmakta buna paralel olarak artan oksijen ihtiyacını karşılayacak olan solunum sisteminin fizyolojik uyumu ortaya çıkmaktadır (Akgün, 1989, Tamer, 1995, Tanalp, 1971).

Aerobik kapasite, sporcuların çalışma kapasitelerini belirleyen fizyolojik kriter olarak kullanılmaktadır. Aerobik gücü geliştiren antrenmanların, aynı zamanda vücut kompozisyonunu, istirahat kalp atım sayısı ve kan basınçlarını da düzenlemede faydalı olduğu bilinmektedir (Israel, 1993).

Oksijen kanda büyük oranda hemoglobine bağlı olarak taşınır. Az bir kısmı ise erimiş haldedir. Kandaki oksijenin hemoglobine bağlı olarak taşınan miktarına oksijen satürasyonu (SpO2) denir (Acartürk, 2009).

$\mathrm{Bu}$ araştırmanın amacı, farklı yükseltideki illerde bulunan U13 kategorisi futbolcuların müsabaka şartlarında nabız ve oksijen saturasyon değerlerinin incelenmesidir.

\section{Yöntem}

\section{Araştıma Grubu}

Bu çalışmanın araştırma grubunu Ankara'da bulunan Keçiören Bağlum sporun U13 futbol takımı ( $\mathrm{n}=17)$ ve Isparta da bulanan Iyaş Gençlik ve Sporun U13 futbol takımında oynayan ( $\mathrm{n}=17)$ toplam 34 futbolcu oluşturmaktadır.

Çalışmaya katılan Ankara Bağlum Spor Kulübü oyuncularının boy ortalamaları 152,7士5,6

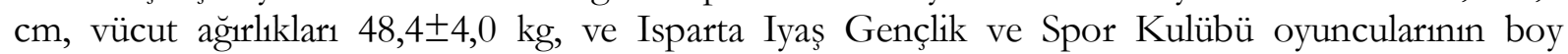
ortalamalar1 156,1 $\pm 6,1 \mathrm{~cm}$, vücut ağırlıkları ise $47,0 \pm 3,7 \mathrm{~kg}$ olarak tespit edildi. Futbolculara araştırma hakkında bilgi verilmiş ve çalışma öncesinde motivasyonları yükseltilmiştir. 
Bağıș, Y. E., \& Kumartaşlı, M. (2017). Farklı yükseltideki illerde bulunan u13 kategorisi futbolcuların müsabaka ortamında nabız ve oksijen saturasyon değerlerinin incelenmesi. Journal of Human Sciences, 14(2), 1975-1982. doi:10.14687/jhs.v14i2.4133

\section{Boy Ölçümü}

0,1 mm hassasiyete sahip olan SEGA marka boy skalası ile ölçüldü.

\section{Vücut Ağırlıkları Ölçümü}

Hassasiyeti 0,5 kg olan SEGA marka elektronik baskül ile çocukların üzerinde sadece şort ve tişört varken çıplak ayak ile tartılarak alındı.

\section{Kalp Atım Sayılarının ve Oksijen Satürasyonu Ölçümü (SpO2 )}

Oksijen satürasyonu, oksijenlenmiş hemoglobinin total geçerli hemoglobine veya fonksiyonel hemoglobine oranı ile hesaplanır. Pulse oksimetre, arteriyel kanda oksijenlenmiş hemoglobin yüzdesini belirler ve bu yolla elde edilen bulgu oksijen satürasyonu olarak bilinir. Pulse oksimetre, arteriyel kandaki oksijen satürasyonunun noninvaziv bir şekilde ölçülmesine yarayan bir araçtır. Pulse oksimetreler dokudaki nabzın arteryel kan tarafindan oluşturulduğunu göz önüne alarak, infrared ışığın pusatil frekansının absorbsiyonu ile infrared sşığın sadece iki dalga boyu ile ölçülebileceği prensibi ile çalışmaktadır (Pole, 2002, Tosun ve Tutluoğlu, 2000).

Önceleri hastaların oksijenlenmesini değerlendirmek için en sık kullanılan yöntem arteriyel kan gazı ölçümleriydi. Günümüzde ise pulse oksimetre, oksijenlenmeyi değerlendirmek için kullanılan basit ve güvenilir bir yöntemdir. Kan almaya alternatif olan, güvenli, ağrısız, kullanımı kolay ve çabuk sonuç veren bir uygulamadır. Bu avantajlar oksimetreyi, kişinin oksijene olan ihtiyacını belirlemede ve uygulanan tedavinin etkinliğini değerlendirmede önemli bir araç yapmaktadır. \%95'in üzerindeki oksijen satürasyonu değeri normal kabul edilirken, \%093’ten az olan değerler oksijen tedavisinin gerekli olduğunu işaret eder ve kişinin daha yakından izlenmesini gerektirir ( Akansel ve Yıldız, 2010). Çalışmada futbolcuların nabız ve oksijen saturasyon değerlerinin belirlenmesi için ölçümleri Pulse Oksimetre (Nellcor Puritan Bennet NPB - 40 marka pulse oksimetre) kullanılarak alınmıştır. Futbolculara antrenman maçı yaptırllıp ölçümler maç başlangıcında, maçın 10. dakikası, 20. dakikası, 30. dakikası ve 40. dakikası olmak üzere toplam 5 ölçüm alınmıştır.

\section{Verilerin Analizi}

Araştırma verilerinin analizi SPSS 18.0 istatistik paket programı kullanılarak yapıldı istatistiksel analiz de ise tanımlayıc istatistikler ve Independent $\mathrm{t}$ testi kullanıldı. Önem derecesi "p $<0.05$ " olarak kabul edildi.

\section{Bulgular}

Tablo 1. U13 Ankara Bağlum Spor Kulübü ve Isparta Iyaş Gençlik ve Spor Kulübü Sporcularının Fiziksel Bilgileri

\begin{tabular}{lcc}
\hline Parametreler $(\mathrm{n}=34)$ & İ & Art.Ort \pm SS \\
\hline \multirow{2}{*}{ Boy $(\mathrm{cm})$} & Isparta & $156.1 \pm 6,1$ \\
\cline { 2 - 3 } & Ankara & $152,7 \pm 5,6$ \\
\hline \multirow{2}{*}{ Vücut Ağırlığ $(\mathrm{kg})$} & Isparta & $47,0 \pm 3,7$ \\
\cline { 2 - 3 } & Ankara & $48,4 \pm 4,0$ \\
\hline
\end{tabular}

Araştırmaya katılan sporcuların boy ortalaması Isparta Iyaş Gençlik ve Spor Kulübünde

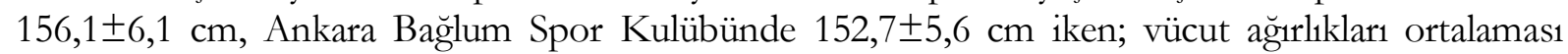

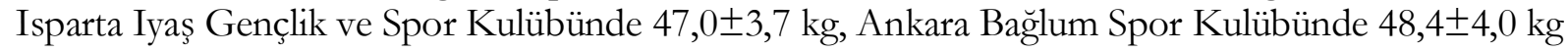
olarak tespit edildi. 
Bağış, Y. E., \& Kumartaşlı, M. (2017). Farklı yükseltideki illerde bulunan u13 kategorisi futbolcuların müsabaka ortamında nabız ve oksijen saturasyon değerlerinin incelenmesi. Journal of Human Sciences, 14(2), 1975-1982. doi:10.14687/jhs.v14i2.4133

Tablo 2. Sporcularının Müsabaka Öncesi ve Esnasında Kalp Atım Sayılarının Karşılaştırılması

\begin{tabular}{|c|c|c|c|c|}
\hline Kalp Atım Sayısı (atım/dk) & İ1 & Art.Ort \pm SS & $\mathbf{T}$ & $\mathrm{p}$ \\
\hline \multirow{2}{*}{ Müsabaka Öncesi } & Isparta & $99,2 \pm 15,2$ & \multirow[b]{2}{*}{, 029} & \multirow[b]{2}{*}{977} \\
\hline & Ankara & $99,4 \pm 20,4$ & & \\
\hline \multirow{2}{*}{ Müsabakanın 10. Dk } & Isparta & $120,2 \pm 15,2$ & \multirow{2}{*}{1,91} & \multirow{2}{*}{065} \\
\hline & Ankara & $133,2 \pm 23,3$ & & \\
\hline \multirow{2}{*}{ Müsabakanın 20. Dk } & Isparta & $117,7 \pm 45,9$ & \multirow[b]{2}{*}{1,99} & \multirow[b]{2}{*}{, 054} \\
\hline & Ankara & $138,9 \pm 23,6$ & & \\
\hline \multirow{2}{*}{ Müsabakanın 30. Dk } & Isparta & $135,5 \pm 31,3$ & \multirow[b]{2}{*}{1,40} & \multirow[b]{2}{*}{1,69} \\
\hline & Ankara & $144,7 \pm 21,5$ & & \\
\hline \multirow{2}{*}{ Müsabakanın 40. Dk } & Isparta & $145,2 \pm 27,6$ & \multirow[b]{2}{*}{,- 965} & \multirow[b]{2}{*}{,342 } \\
\hline & Ankara & $137,7 \pm 16,9$ & & \\
\hline
\end{tabular}

U13 Ankara Bağlum Spor Kulübü ve Isparta Iyaş Gençlik ve Spor Kulübü Sporcularının Müsabaka Öncesi ve Esnasında Kalp Atım Sayılarının ölçümlerinde istatistiksel açıdan anlamlı fark bulunmamıstır ( $\mathrm{p}>0.05)$.

Tablo 3. U13 Ankara Bağlum Spor Kulübü ve Isparta Iyaş Gençlik ve Spor Kulübü Sporcularının Müsabaka öncesi ve Esnasında Oksijen Saturasyonunun Karşılaştırılması

\begin{tabular}{|c|c|c|c|c|}
\hline Oksijen Saturasyonu (\%) & İl & Art.Ort \pm SS & $\mathbf{T}$ & $\mathrm{p}$ \\
\hline \multirow{2}{*}{ Müsabaka Öncesi } & Isparta & $95,4 \pm 3,0$ & \multirow{2}{*}{2,20} & \multirow{2}{*}{,035 } \\
\hline & Ankara & $97,1 \pm 1,1$ & & \\
\hline \multirow{2}{*}{ Müsabakanın 10. Dk } & Isparta & $95,7 \pm 4,1$ & \multirow{2}{*}{,372 } & \multirow{2}{*}{, 712} \\
\hline & Ankara & $96,1 \pm 2,0$ & & \\
\hline \multirow{2}{*}{ Müsabakanın 20. Dk } & Isparta & $95,1 \pm 2,2$ & \multirow{2}{*}{1,74} & \multirow{2}{*}{090} \\
\hline & Ankara & $96,2 \pm 1,6$ & & \\
\hline \multirow{2}{*}{ Müsabakanın 30. Dk } & Isparta & $90,1 \pm 5,7$ & \multirow{2}{*}{4,34} & \multirow{2}{*}{, 000} \\
\hline & Ankara & $96,2 \pm 1,3$ & & \\
\hline Müsabakanın 40. Dk & Isparta & $98,5 \pm 14,1$ &,- 497 & ,623 \\
\hline
\end{tabular}

Ankara Bağlum Spor Kulübü ve Isparta Iyaş Gençlik ve Spor Kulübü oyuncularının müsabaka öncesi ve müsabakanın 30. Dakikasında oksijen saturasyonu ölçümlerinin karşılaştırılmasında istatiksel açıdan anlamlı fark bulunurken $(\mathrm{p}<0.05)$, müsabakının öncesi ve 10 , 20., 40. dakiklardaki oksijen saturasyonu ölçümlerinin karşılaştırllması sonucunda ise fark istatistiksel açıdan anlamlı fark bulunamamıştır ( $\mathrm{p}>0.05)$.

\section{Tartışma}

$\mathrm{Bu}$ araştırmada, Ankara Bağlum Spor Kulübü (n=17) ve Isparta Iyaş Gençlik ve Spor Kulübü (n=17) U13 kategorisinde oynayan toplam 34 erkek futbolcu çocukların müsabaka şartlarında nabız ve oksijen saturasyon değerleri incelenmiştir.

Araştırmaya katılan sporcuların boy ortalaması Isparta Iyaş Gençlik ve Spor Kulübünde

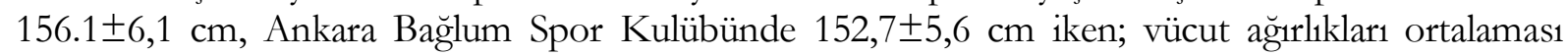

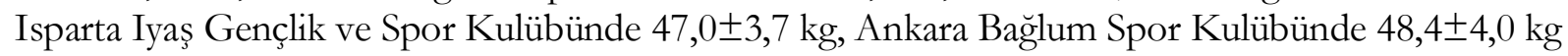
olarak tespit edildi.

Etkili bir antrenman, kişinin yapısına uygun olan fiziksel yöntemlerin kullanılmasına, ayrıca spor dalının fiziksel ve fizyolojik ihtiyaçlarına dayanmalıdır (Günay, 1993). Futbolcuların yüksek seviyedeki fizyolojik özellikleri, bilim adamları ve antrenörler tarafindan ilgi ile takip edilmekte ve bu 
Bağıș, Y. E., \& Kumartaşlı, M. (2017). Farklı yükseltideki illerde bulunan u13 kategorisi futbolcuların müsabaka ortamında nabız ve oksijen saturasyon değerlerinin incelenmesi. Journal of Human Sciences, 14(2), 1975-1982. doi: $10.14687 /$ ihs.v14i2.4133

olgunun önemi de gittikçe artmaktadır. Sporda başarı için sporcunun fizyolojik ve motorik özellikleri yönünden üst seviyede performans sergilemesi gerekir.

Yapılan çalışmada, Ankara Bağlum Spor Kulübü oyuncularının müsabaka öncesinde KAS 99,4 $\pm 20,4$ atım/dk. müsabakanın 10.dakikasında KAS 133,2 $\pm 23,3$ atım/dk., müsabakanın

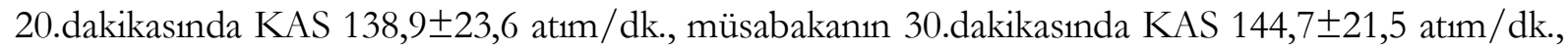

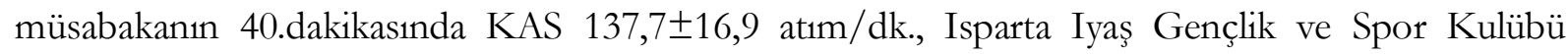
oyuncularının ise; müsabaka öncesinde KAS 99,2 $\pm 15,2$ atım/dk. müsabakanın 10.dakikasında KAS

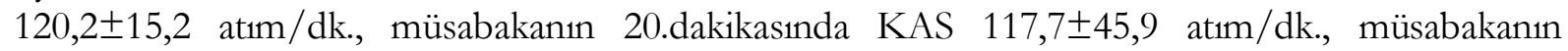

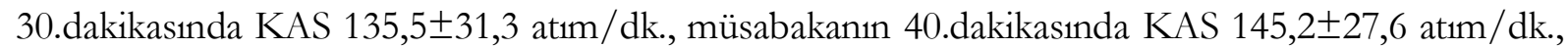
olarak bulundu. Ankara Bağlum Spor Kulübü ve Isparta Iyaş Gençlik ve Spor Kulübü U13 kategorisinde oynayan futbolcuların Kalp Atım Sayılarının gruplar arası karşılaştırmada istatistiksel açıdan anlamlı fark bulunmamıstır $(\mathrm{p}>0,05)$.

Kürkçü ve ark. (2009)'da, 10-12 yaş grubundaki futbolcu ve badmintoncularda bazı fiziksel

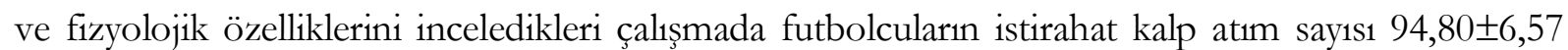
atım/dk olarak bulmuşlardır.

Alpay ve ark.(2008)'de İlköğretim Okul Takımlarında Yer Alan 11-13 Yaş Gurubu Öğrencilerin Bazı Solunum ve Dolaşım Parametrelerinin Spor Yapmayan Öğrencilerle Karşılaştırdıkları çalışmalarında spor yapanların dinlenik KAS 79,55 $\pm 8,24$ atım/dk olarak tespit etmişlerdir.

Şahin (2011)'de Taekwondocularda Kalp Atım Hızı ve Kan Laktat Konsantrastonundaki

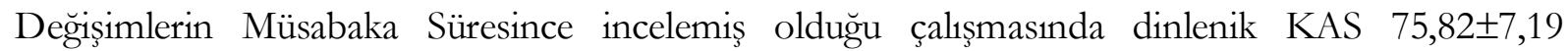

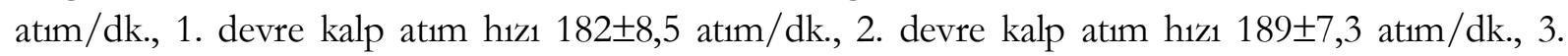
devre kalp atım hızı 193 $\pm 6,55 \mathrm{atım} / \mathrm{dk}$ olarak tespit etmiştir.

Danimarkalı üst düzey futbolcuların maç süresince kalp atımları incelendiğinde, maksimum kalp atımları 150 atım/dakika ile 190 atım/dakika arasında değiştiği ve maç içerisinde kısa dönemlerde kalp atımının 150 atım/dakika altına düştüğü bildirilmiştir (Bangsbo, 2004). Yaptığımız çalışmayı literatürle karşılaştırdığımızda kalp atım sayıları benzer niteliktedir.

Gökbel ve arkadaşlarının ikinci lig futbolcuları üzerinde yapmış olduğu çalışmada istirahat kalp atım sayıs $59 \pm 8$ atım/dk olarak bulmuşlardır. Bu çalışmanın bizim çalışmamızdan farklı olmasının sebebi olarak yaşlarının büyük olmasından kaynaklandığını düşünülmektedir.

Solunan havadaki oksijeninin azlığı, kassal hastalıklara bağlı olarak solunum etkinliğinin azalması, akciğerlere alınan hava miktarının yetersizliği, hava yolu direncinin azalmasına bağlı olarak meydana gelen solunum sorunların kaynağı olan doku oksijenasyonunun yetersizliği anlamına gelen hipoksinin erken verisi oksijen saturasyonudur. Arteriyel kan hemoglobinin oksijene duygunluğu sporcu bireyler için hayati bir önem sahip olduğu bilinmektedir (Özdal ve ark., 2014).

Yapılan çalışmada, Ankara Bağlum Spor Kulübü oyuncularının müsabaka öncesinde spo2 saturasyonu, 97,1 $\pm 1,1 \%$, müsabakanın 10.dakikasında spo2 saturasyonu $96,1 \pm 2,0 \%$, müsabakanın 20.dakikasında spo2 saturasyonu 96,2 $\pm 1,6 \%$, müsabakanin 30.dakikasinda spo2 saturasyonu $96,2 \pm 1,3 \%$, müsabakanın 40.dakikasında spo2 saturasyonu 96,8 $\pm 1,0 \%$, Isparta Iyaş Gençlik ve Spor kulübü oyuncularının ise müsabaka başlangicinda spo2 saturasyonu, $95,4 \pm 3,0 \%$,

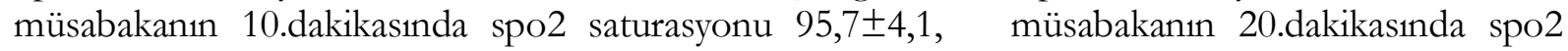
saturasyonu $95,1 \pm 2,2 \%$, müsabakanın 30. dakikasında spo2 saturasyonu $90,1 \pm 5,7 \%$, müsabakanın 40. dakikasinda spo2 saturasyonu 98,5 $\pm 14,1 \%$ olarak tespit edildi.

Ankara Bağlum Spor Kulübü ve Isparta Iyaş gençlik ve spor kulübü oyuncularının müsabaka öncesi ve müsabakanın 30. Dakikasında oksijen saturasyonu ölçümlerinin karşılaştırılmasında istatiksel açıdan anlamlı fark bulunurken $(\mathrm{p}<0.05)$, bunun sebebi olarak; her iki takımın uygulamış olduğu antrenman programında antrenman kapsamında farklilıklar olduğunu düşünmekteyiz. müsabakının öncesi ve 10., 20., 40. dakiklardaki oksijen saturasyonu ölçümlerinin karşılaştırılması sonucunda ise fark istatistiksel açıdan anlamlı fark bulunamamışır $(\mathrm{p}>0.05)$. 
Bağıș, Y. E., \& Kumartaşlı, M. (2017). Farklı yükseltideki illerde bulunan u13 kategorisi futbolcuların müsabaka ortamında nabız ve oksijen saturasyon değerlerinin incelenmesi. Journal of Human Sciences, 14(2), 1975-1982. doi:10.14687/jhs.v14i2.4133

Sarıtaş ve ark.(2013), Futbol oyuncularında antioksidan ve oksidan üzerine E vitaminin etkisini inceledikleri çalışmasında antrenman öncesi $97.60 \pm 0.32 \%$, antrenman sonrası ise $97.13 \pm 0.38 \%$ olarak bulmuşlardır.

Özdal ve ark. (2014)'de Aerobik Antrenmanın Arteriyel Hemoglobin Oksijen Satürasyonu Üzerine Etkisi inceledikleri çalısmalarında deney grubunun ön test ve son test verilerine

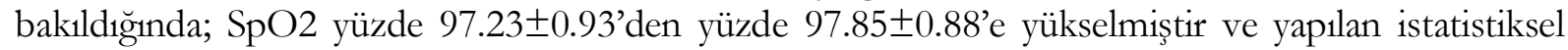
analiz sonucunda T1 ile T2 arasında $\mathrm{p}$ düzeyinde anlamlılık bulunmuştur $(\mathrm{p}=0.032)$. Aynı çalışmada kontrol grubunun ön test ve son test verilerine bakıldığında; SpO2 yüzde 96.58 \pm 0.89 'den yüzde 96.96 \pm 0.64 'ya yükselmiştir ve yapılan istatistiksel analiz sonucunda T1 ile T2 arasinda $\mathrm{p}<0.05$ düzeyinde anlamlılık bulunmuştur $(\mathrm{p}=0.044)$. Bu iki anlamlılı̆ın; aerobik egzersize bağlı olarak solunum kaslarının gelişmesi, solunum hacminin artması uygun ventilasyon perfüzyon oranın sağlanması, miyokart hipertrofisi ve kalp debisinin artması sonucu kan oksijen içeriğinin (cao2) yoğunlaşması ve egzersizin kan hemoglobin sayısını da artmasıyla birlikte meydana geldiğini düşünmektedirler.

\section{Sonuç}

Sonuç olarak; aerobik sistemin yoğun olduğu branşlarda sporcular performanslarını daha uzun sürdürebilmesi için SpO2 ölçümleri önemlidir. Buna dayanarak çalışmamız daha önce literatürde az çalışıldığından dolayı çalışmanın önemini arz etmektedir. Elde edilen verilere dayanarak çalışmamız, oksijen saturasyonu ile ilgili ileride yapılacak olan çalışmalara ışık tutacaktır. Bazı farklılıkların veya benzerliklerin netleşebilmesi için daha fazla yükselti belirginliği olan yerlerde ve gruplar üzerinde çalışılmasının yararlı olacağını düşünülmektedir.

\section{Kaynakça}

Acartürk E. (2009), KOAH Hastalarındaki Oksijen Satürasyonunun Pulse Oksimetre ile Tesbitinin Arter Kan Gazı Tetkiki ile Korelasyonu ve Bu Korelasyonu Etkileyen Faktörler. Uzmanlık Tezi, Süreyyapaşa Göğüs Kalp ve Damar Hastalıkları Eğitim ve Araştırma Hastanesi, İstanbul.

Akansel N, Yıldız H. Pulse oksimetre değerlerinin güvenilir olması için neleri bilmeliyiz? Türkiye Klinikleri, Journal of Anaesthesiology \& Reanimation, 2010, 8(1): 44-8.

Akgün N. Egzersiz Fizyolojisi, Gökçe Ofset Matbaacillk, 1989, Ankara s 70-72

Bangsbo, J.,(2004), Fitness Training In Soccer: A Scientific Approach. Publisher: Reedswain.

Berkan A., Kamil A., Serkan H. (2008), İlköğretim Okul Takımlarında Yer Alan 11-13 Yaş Gurubu Öğrencilerin Bazı Solunum ve Dolaşım Parametrelerinin Spor Yapmayan Öğrencilerle Karşılaştırılarak Değerlendirilmesi, Mehmet Akif Ersoy Üniversitesi Eğitim Fakültesi Dergisi.

Gökbel H, Yalaz G, Güvel H,. Şemin S, Tamuğur E, Özgönül H., (1990), Bir Profesyonel İkinci Lig Futbol Takımının Fiziksel ve Fizyolojik Profili, Spor Hekimliği Dergisi, 25: 35- 37

Günay M., (1993), Farklı Kuvvet Antrenman Metotlarının Vücut Kompozisyonuna Etkisi, Doktora Tezi, Gazi Üniversitesi, Sağlık Bilimleri Enstitüsü, Ankara, s: 8-12

Hickson,R. C., Rosenkdetter, M.A. (1981), Reduced Training Freguencies and Maintenance of Increased Aerobik Power, Med. And Science in Sports and Exercise, s:13-16.

Israel, R.,G. (1993): Infulance of Cardiorespiratory Fitness on Measure of Obesity an Fat Distribution in Man, Med. and Science in Sport and Exercise, 25 (5),152

Kurdak SS. Solunum sistemi maksimal egzersiz kapasitesini sınırlar m1? Solunum, 2012,14:12-20 (suppl).

Kürkçü, R., Özdağ, S., Afyon, Y. A., Yaman, Ç. (2009), 10-12 Yaş Grubundaki Futbolcu ve Badmintoncularda Bazı Fiziksel ve Fizyolojik Özelliklerinin Karşılaştırılması. Uluslararası İnsan Bilimleri Dergisi [Bağlantıda]. 6:1. Erişim: http://www.insanbilimleri.com. 
Bağıș, Y. E., \& Kumartaşlı, M. (2017). Farklı yükseltideki illerde bulunan u13 kategorisi futbolcuların müsabaka ortamında nabız ve oksijen saturasyon değerlerinin incelenmesi. Journal of Human Sciences, 14(2), 1975-1982. doi:10.14687/jhs.v14i2.4133

McArdle WD, Katch FI, Katch VL. Exercise Physiology Energy, Nutrition \&Human Performance, 6th Ed. Baltimore, Lippincott Williams \& Wilkins, 2007,469-508.

Özdal M.,(2014), Önder D., Tuncer D., Nadide Ö., Aerobik Antrenmanın Arteriyel Hemoglobin Oksijen Satürasyonu Üzerine Etkisi, Spor ve Performans Araştırmaları Dergisi, Cilt / Vol : 5 Say1 / No :1

Pole Y. Evolution of pulse oximeter. International Congress Series, 2002, 1242, 137-144

Sarıtaş N., Nakaç A., Yazıcı C., Büyükipekçi S., Coşkun B. (2013), Effect Of Vitamın E On Oxıdant And Antioxidant Capacity In Football Players, Nigde University Journal Of Physical Education And Sport Sciences Vol 7, No 2.

Şenay Ş. (2011), Taekwondocularda Kalp Atım Hızı ve Kan Laktat Konsantrastonundaki Değişimlerin Müsabaka Süresince İncelenmesi, Selçuk Üniversitesi, Sağllk Bilimleri Enstitüsü, Antrenörlük Eğitimi Ana Bilim Dal, Yüksek Lisans Tezi, Konya.

Tamer K. Sporda Fiziksel Fizyolojik Performansın Ölçülmesi ve Değerlendirilmesi, Türkerler Kitabevi, Ankara 1995, s 67-68.

Tanalp R. Solunum Sistemi Fizyolojisi, AÜ.Basımevi, 1971, Ankara

Tosun GA, Tutluoğlu B. Arter kan gazları ve asit baz dengesi. Solunum, 2000, 2: 202-213.

\section{Extended English Abstract}

Among the decisive factors that uplift sporty success during prolonged and high-temp physical activity is the possible counting of maximal oxygen (MaxVO2) intake. The ability to use oxygen, one of the most important criteria to determine success during physical activity, particularly at aerobic metabolism, is the ability of the mitochondria to function in the skeletal muscle cells.It is known that exercises which improve aerobic power is also useful for regulating body composition, heart rate at rest and blood pressure (Israel, R.,G., 1993). Most oxygen is carried through blood by hemoglobine. Only a little portion of it is dissolved. The amount of oxygen which is carried by hemoglobine in the blood is termed oxygen saturation (SpO2) (Acartürk 2009). The aim of this study is to investigate the heart rate and oxygen saturation values of U13 footballers at competition occasion who stand in different cities. 34 footballers participated to the study totally who are playing U13 teams of Ankara Keçiören Bağlum Sport Club and Isparta Iyaş Youth and Sport Club. The average height and weight of the players from a sport club in Ankara (Ankara Bağlum Sports Club) were found as $152,7+5.6 \mathrm{~cm}$ and $48,4+4,0 \mathrm{~kg}$ respectively and for the players from a local sports club in Isparta (Iyaş Youth and Sports Club) were determined to be 156,1+6.1 cm and $47,0+3.7$ respectively. Before the study, the players were given information about the study and some effort was made in order to increase their motivation. In order to determine the players' heart rate and oxygen saturation values, measurements were done with a pulse oximeter (Nellcor Puritan Bennet NPB-40). The research data were analyzed by using SPSS 18.0 statistics package program. Descriptive statistics and Independent $t$ test were used for the statistical analysis. The significance level was taken as " $\mathrm{p}<0.05$ ". The players played a practice match and their values were measured before the match, at the 10th, 20th, 30th and 40th minutes. Research Groups' height means found in Isparta Iyaş Youth and Sport Club 156.1 $\pm 6,1 \mathrm{~cm}$, found in Ankara Bağlum Sport Club $152,7 \pm 5,6 \mathrm{~cm}$; weight means found in Isparta Iyaş Youth and Sport Club 47,0 $\pm 3,7 \mathrm{~kg}$, Ankara

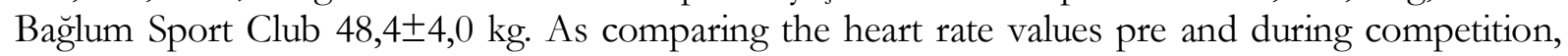
differences found insignificiant too $(\mathrm{p}>0.05)$. While comparing the oxygen saturation measurements in pre and $30^{\text {th }}$ minute, differences were found statistically significiant $(p<0.05)$; in other comparison of oxygen saturation measurements, differences were found statistically insignificiant ( $p>0.05)$. An effective training must based on application of the physical methods in 
Bağ1ş, Y. E., \& Kumartaşlı, M. (2017). Farklı yükseltideki illerde bulunan u13 kategorisi futbolcuların müsabaka ortamında nabız ve oksijen saturasyon değerlerinin incelenmesi. Journal of Human Sciences, 14(2), 1975-1982. doi:10.14687/jhs.v14i2.4133

compatible with the player's body composition and also on the specific physical and physiological needs which a particular sports require (Günay, 1993). The high level physiological qualities of players are followed by scientists and trainers with great interest and the importance attached to this is increasing gradually. A player must put a high level performance in terms of physiological and motoric qualities in order to achieve success in any sports. Kürkçü and et al (2009) worked on a group of football and badminton players aged 10 to 12 and studied some physical and physiological qualities. They found the heart rate at rest $94,80+6,57$ beat $/ \mathrm{min}$. Alpay et al (2008) worked on a group of elemantary school players aged 11 to 13. In the study, they compared the respiratory and circulatory parameters of the players to those of the pupils who did not do sports. They found heart rate at rest 79,55+8,24 beat/min. Şenay Şahin (2011) studied heart rate and the changes in blood lactate concentration of some taekwondo players during a competition and found heart rate at rest $75,82+7.19$ beat $/ \mathrm{min}$, the first phase heart rate $182+8,5$ beat $/ \mathrm{min}$., the second phase heart rate $189+7,3 \mathrm{beat} / \mathrm{min}$. and the third phase heart rate $193+6,55 \mathrm{beat} / \mathrm{min}$. The inadequate oxygen in the air, the deterioration of breathing ability depending on muscular disorders, inadequacy of the air taken by the lungs. It is known that oxygen saturation of arterial blood hemoglobine is of vital significance for individual players (Özdal et al., 2014). Özdal et al. (2014) studied the effect of aerobic training on arterial hemoglobine oxygen saturation. The pretest and posttest data looks like: SpO2 increased from $97.23+0.93 \%$ to $97.85+0.88$ and a P level significance was found between $\mathrm{T} 1$ and $\mathrm{T} 2$ after a statistical analysis $(\mathrm{p}=0.032)$. When we study the pretest and posttest data for the control group, we see that SpO2 rose from $96.58+0.89$ percent to $96.96+0.64$ and $\mathrm{p}<0.05$ level significance was determined between $\mathrm{T} 1$ and $\mathrm{T} 2$ after a statistical analysis $(\mathrm{p}=0.044)$. It is thought that the two significance found between T1 and T2 may be due to the fact that respiratory muscles have been strengthened thanks to the aerobic exercises, the increase in the volume of respiration, the provision of the right rate of ventilation perfusion, the concentration of oxygen in the blood (cao2) owing to the myocardial hypertrophy and heart output increase and exercise boosting the count of hemoglobine in blood. Based on the obtained data, we think that studying with more higher areas and groups will be useful for sharpening some differences and similarities. 